\title{
Effects of Turbulence on the Combustion Properties of Partially Premixed Flames of Canola Methyl Ester and Diesel Blends
}

\author{
N. Dhamale, R. N. Parthasarathy, and S. R. Gollahalli \\ School of Aerospace and Mechanical Engineering, The University of Oklahoma, Norman, OK 73019-1052, USA \\ Correspondence should be addressed to S. R. Gollahalli, gollahal@ou.edu
}

Received 12 January 2011; Accepted 14 March 2011

Academic Editor: Alexey A. Burluka

Copyright () 2011 N. Dhamale et al. This is an open access article distributed under the Creative Commons Attribution License, which permits unrestricted use, distribution, and reproduction in any medium, provided the original work is properly cited.

Canola methyl ester (CME) is a biofuel that is a renewable alternative energy resource and is produced by the transesterification of canola oil. The objective of this study was to document the effects of turbulence on the combustion characteristics of blends of CME and No 2 diesel fuel in a partially-premixed flame environment. The experiments were conducted with mixtures of prevaporized fuel and air at an initial equivalence ratio of 7 and three burner exit Reynolds numbers, 2700, 3600, and 4500. Three blends with 25,50, and 75\% volume concentration of CME were studied. The soot volume fraction was highest for the pure diesel flames and did not change significantly with Reynolds number due to the mutually compensating effects of increased carbon input rate and increased air entrainment as the Reynolds number was increased. The global NOx emission index was highest and the $\mathrm{CO}$ emission index was the lowest for the pure CME flame, and varied non-monotonically with biofuel content in the blend The mean temperature and the NOx concentration at three-quarter flame height were generally correlated, indicating that the thermal mechanism of NOx formation was dominant in the turbulent biofuel flames also.

\section{Introduction}

Rising oil prices, national security concerns, and protection of the environment have resulted in research and development of alternative fuels. Biofuels form one category of alternative fuels that can be used with minor modifications to current automobiles. Biofuels are renewable and available in the US, and they have energy content similar to petroleumbased gasoline and diesel. One category of biofuels is derived from the transesterification of vegetable oils, such as canola and soy oil; examples of such biofuels are soy methyl ester (SME) and canola methyl ester (CME). These fuels are low in sulfur and can be produced locally; also, they result in reduced net carbon emissions.

There have been a number of studies on the use of these biofuels in diesel engines. Durbin et al. [1] measured the pollutant emissions and particulate matter (PM) from four commercially available diesel vehicles. The engines were operated on diesel, B100 (100\%) biofuel, B80 (80\% biofuel by volume) biofuel, and synthetic diesel fuels. In three of the four vehicles tested, there were no significant differences in the particulate matter (PM) emitted from engines using
B100 and diesel fuels. Scholl and Sorenson [2] tested soy methyl ester in a four-cylinder, four-stroke cycle, normally aspirated direct-injection diesel engine and compared the results to those obtained with conventional diesel fuel. The authors found that the results varied with engine operating conditions, such as ignition delay and cylinder pressure rise. McCormick et al. [3] tested various biofuel and diesel fuels in a six-cylinder, direct-injected, turbocharged, four-stroke cycle engine. Particulate matter per unit power was measured and was found to be significantly less (by 300\%) than that obtained with the use of petroleum-based diesel. Wang et al. [4] tested B35 (35\% biofuel by volume) soy methyl ester biofuel blends in unaltered Cummins tractor truck engines and measured the resulting PM and pollutant emissions. It was shown that $25 \%$ less PM was produced when the engines were operated using the blended mixture than when operated on petroleum diesel.

Dorado et al. [5] used transesterified waste olive oil in a $2500 \mathrm{cc}$, three-cylinder, four-stroke cycle, water-cooled, direct-injection diesel engine. The authors showed that by using biofuels, $\mathrm{CO}$ emission was reduced by up to $58.9 \%$, and NO emission was increased up to $37.5 \%$ when compared to 
the emissions obtained with the use of petroleum diesel. Also, $\mathrm{CO}$ emissions were shown to correlate with the production of PM. Labeckas and Slavinskas [6] conducted studies on naturally aspirated, four-stroke, four-cylinder, water-cooled direct-injection diesel engine with diesel fuel and cold pressed rapeseed oil (RO). An increase in the NOx emissions was observed with the use of rapeseed oil. The increase in NOx formation was attributed to the double bonds present in the fuel and the longer ignition delay caused due to the presence of rapeseed fatty acid. Agarwal [7] reviewed the production, characterization, and current statuses of vegetable oil, biofuel, and alcohols as well as the experimental research work carried out in various countries. The low $\mathrm{CO}$ emissions from methyl esters in comparison to raw vegetable oil were attributed to better spray quality. Mueller et al. [8] investigated the increase in NOx emission in a heavyduty compression ignition engine with soy biofuel. Results suggested that the NOx increase observed with the use of biofuels was not quantitatively determined by a change in a single fuel property, but rather was the result of a number of coupled mechanisms whose effects may tend to reinforce or cancel one another under different conditions, depending on the specific combustion and fuel characteristics. Due to the oxygenated nature of biofuel, the soot production was suppressed, which reduced the total radiative heat losses in the cylinder, thereby increasing the temperatures and thermal NOx production. Kousolidou et al. [9] studied the performance of B10 biodiesel fuel of palm oil in a lightduty common-rail Euro 3 engine. It was found that the use of biodiesel blends resulted in a reduction in PM emissions whereas the effects on NOx emissions were only marginally different from those measured with petroleum diesel. It was concluded that blends of up to $10 \%$ biodiesel could be used in current diesel engines without any significant effects on the performance.

A limited number of studies have been conducted to document the combustion properties of biofuels in an openflame environment. Love et al. [10] measured the radiative heat flux and the emissions from laminar partially premixed flames of prevaporized mixtures of various fuels with air. The emission indices of NOx and CO of both petroleum-derived and biofuels agreed well with those measured in engines, as reported in the literature. In a companion study, Love et al. [11] used the same experimental configuration to study the effect of iodine number on NOx formation in laminar partially premixed flames of canola methyl ester, soy methyl ester, and methyl stearate. It was found that the peak NOx concentration increased significantly with the fuel iodine number, indicating a strong correlation between the chemical structure of the fuel and the NOx emission. It was also concluded that the Fenimore mechanism (not the Zeldovich mechanism) was the dominant route in NOx production in laminar fuel rich biofuel flames. Erazo et al. [12] investigated the combustion properties of canola methyl ester and petroleum diesel spray flames at atmospheric pressure. The drop size and velocity distribution, in-flame temperature, and emissions were measured. Whereas the diesel spray flame burned in a mostly heterogeneous combustion mode, the canola methyl ester underwent homogeneous gas-phase combustion. The NO concentration was lower in the CME flame at all flame heights than that of the diesel spray flame. The CME flame was also cooler (by $200 \mathrm{~K}$ ) than the diesel spray flame. The reduction in NOx emissions observed was in contrast to the NOx increase recorded in previous engine studies and was attributed to the continuous combustion in the spray flame as opposed to the intermittent combustion that occurred in engines.

\section{Objective}

The present experimental investigation is an extension of the studies by Love et al. $[10,11]$ and is aimed at understanding the effects of turbulence on the combustion characteristics of vaporized blends of $\mathrm{CME} /$ diesel flames. The specific objectives of this research project are to measure the global radiation, global emissions, in-flame emissions, and temperature profiles in flames of blended CME and No. 2 diesel fuel under turbulent conditions.

\section{Experimental Detail and Procedure}

3.1. Experimental Setup and Test Conditions. A schematic diagram of the setup is presented in Figure 1. Hightemperature heating tape was used to heat the flow lines carrying air to desired temperatures in order to completely vaporize the liquid fuel. The temperature was regulated using a dual zone temperature controller connected to two K-type thermocouples. One thermocouple was placed just prior to the fuel injection and the other was positioned downstream right before the burner. The air flow was monitored using a digital mass flow meter. The liquid fuel was stored in a tank which was pressurized using a nitrogen cylinder and was metered using a Rotameter. After the air reached the desired temperature, the fuel was injected into the air. The air temperature was set to $460^{\circ} \mathrm{C}$ for all the experiments; this temperature was considerably above the highest boiling point, $420^{\circ} \mathrm{C}$, but below the pyrolysis temperature of CME to enable the complete vaporization of the fuel without coking. The burner had an inner diameter of $9.5 \mathrm{~mm}$ and was fed symmetrically through four bypass ports. All experiments were conducted in a vertical steel test chamber of cross-section $76 \mathrm{~cm} \times 76 \mathrm{~cm}$ and $150 \mathrm{~cm}$ height. The top of the combustion chamber was connected to the atmosphere through an exhaust duct. The ambient pressure of the laboratory was maintained slightly above $(20 \mathrm{~Pa})$ the atmospheric pressure to provide a positive draft inside the test chamber so that the combustion products did not leak into the main laboratory. Additional details of the setup are provided by Dhamale [13].

Three blends of CME and No. 2 diesel fuel in different proportions, B25, B50, and B75 (e.g., B25 is 25\% CME by volume splash blended with $75 \%$ diesel) were tested. The properties of the blends are presented in Table 1 . The oxygen content in the fuel increases with increase in SME concentration in the blend. Also, the heating value decreases as the CME concentration is increased because CME has a lower heating value (by about 10\%) than diesel. Measurements were made for three Reynolds numbers: 2700, 3600, and 4500. The Reynolds numbers (Re) were 


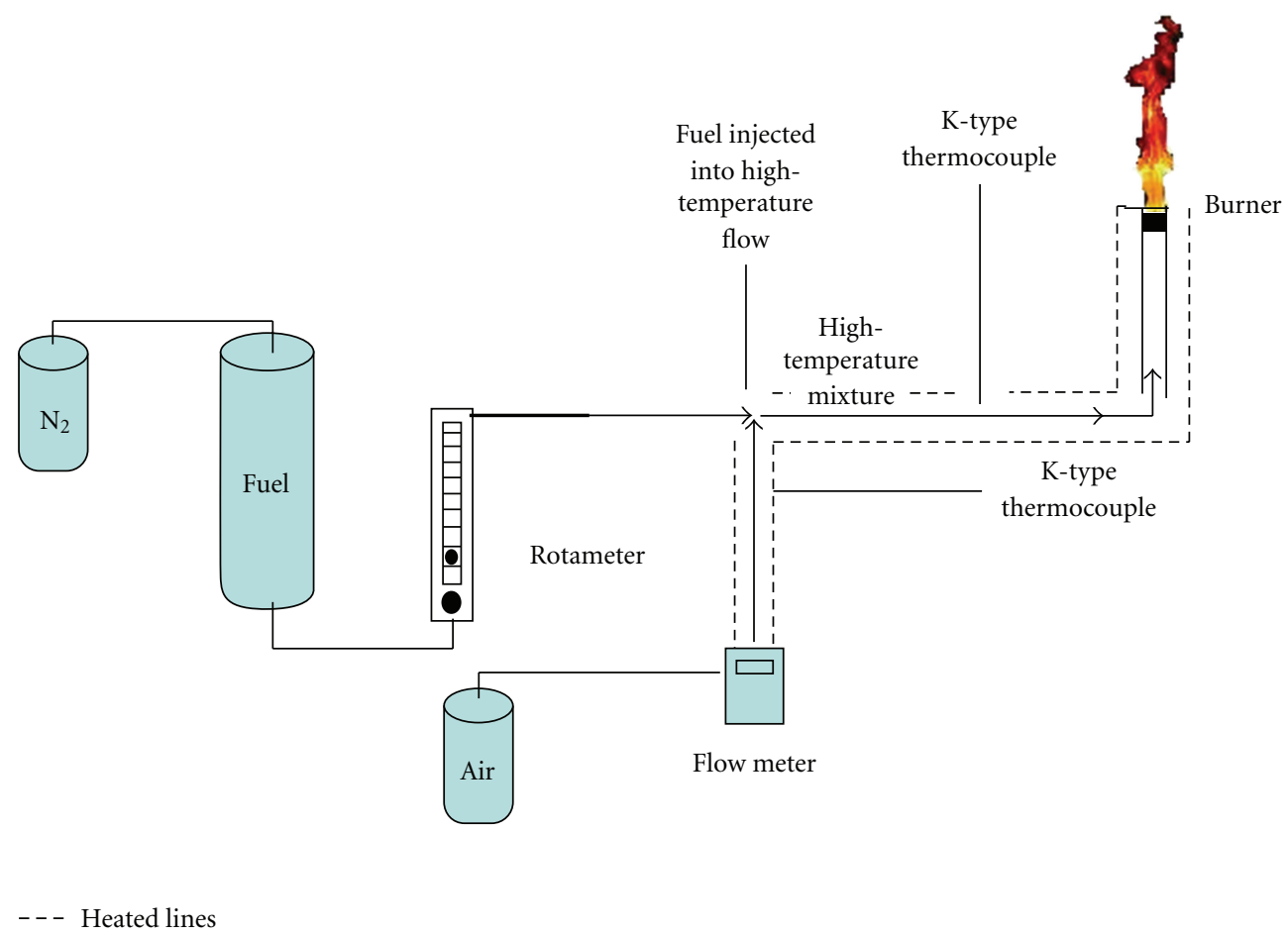

FIGURE 1: Schematic diagram of the experimental setup.

TABLe 1: Fuel properties.

\begin{tabular}{|c|c|c|c|c|c|c|}
\hline Fuel & Reynolds number & Molecular formula & MW (kg/kmole) & Heating value (MJ/kg) & $\% \mathrm{O}_{2}$ & Carbon input rate $(\mathrm{kg} / \mathrm{s})$ \\
\hline \multirow{3}{*}{ CME } & 2700 & \multirow{3}{*}{$\mathrm{C}_{19} \mathrm{H}_{36} \mathrm{O}_{2}$} & \multirow{3}{*}{296} & \multirow{3}{*}{39.8} & \multirow{3}{*}{10.81} & $1.49 E-04$ \\
\hline & 3600 & & & & & $2.00 E-04$ \\
\hline & 4500 & & & & & $2.50 E-04$ \\
\hline \multirow{3}{*}{ CME B75 } & 2700 & \multirow{3}{*}{$\mathrm{C}_{17.52} \mathrm{H}_{32.42} \mathrm{O}_{1.35}$} & \multirow{3}{*}{264.32} & \multirow{3}{*}{40.4} & \multirow{3}{*}{8.18} & $1.53 E-04$ \\
\hline & 3600 & & & & & $2.05 E-04$ \\
\hline & 4500 & & & & & $2.56 E-04$ \\
\hline \multirow{3}{*}{ CME B50 } & 2700 & \multirow{3}{*}{$\mathrm{C}_{16.28} \mathrm{H}_{29.45} \mathrm{O}_{0.82}$} & \multirow{3}{*}{237.97} & \multirow{3}{*}{41.1} & \multirow{3}{*}{5.51} & $1.56 E-04$ \\
\hline & 3600 & & & & & $2.10 E-04$ \\
\hline & 4500 & & & & & $2.63 E-04$ \\
\hline \multirow{3}{*}{ CME B25 } & 2700 & \multirow{3}{*}{$\mathrm{C}_{15.27} \mathrm{H}_{27} \mathrm{O}_{0.38}$} & \multirow{3}{*}{215.88} & \multirow{3}{*}{41.8} & \multirow{3}{*}{2.81} & $1.62 E-04$ \\
\hline & 3600 & & & & & $2.15 E-04$ \\
\hline & 4500 & & & & & $2.69 E-04$ \\
\hline \multirow{3}{*}{ Diesel } & 2700 & \multirow{3}{*}{$\mathrm{C}_{14.4} \mathrm{H}_{24.9}$} & \multirow{3}{*}{197.7} & \multirow{3}{*}{42.6} & \multirow{3}{*}{0} & $1.73 E-04$ \\
\hline & 3600 & & & & & $2.26 E-04$ \\
\hline & 4500 & & & & & $2.81 E-04$ \\
\hline
\end{tabular}

computed based on the bulk fluid velocity, burner inner diameter, and the mixture viscosity. The mixture viscosity was computed using Wilke's equation [14] at the burner exit temperature. The initial equivalence ratio was maintained at 7 , thus, the fuel/air mixture was fuel rich. This condition was chosen to represent the local equivalence ratio in the turbulent diffusion-controlled combustion zone away from the injector in a diesel engine at full-load conditions. Since the mass flow rate was changed to vary the Reynolds number and the equivalence ratio remained constant, the change in Reynolds number was proportional to the change in the bulk velocity of the fuel-air mixture. The carbon input rate increased with the increase in Reynolds number for each fuel, as seen in Table 1. The measurements described below were repeated four to six times, and uncertainties were computed using standard procedures; details of the calculations are presented by Dhamale [13]. The uncertainties are shown as error bars in the relevant figures. 
3.2. Radiation Measurement. Radiation measurements were made with a high-sensitivity pyrheliometer. The pyrheliometer (with a view angle of $150^{\circ}$ and absorptivity of 0.96 ) was placed at a distance of $150 \mathrm{~cm}$ from the burner so that its view angle covered the entire flame length and the inverse square law was satisfied. A data-acquisition board along with suitable software was used to sample the measured radiative heat flux. Each test was run for a duration of 1 minute with a sampling rate of $10 \mathrm{~Hz}$. The background radiative heat flux was sampled for 30 seconds at $10 \mathrm{~Hz}$. The background radiation was subtracted from the measured heat flux to obtain the modified radiative heat flux of the flame. The modified radiative heat flux, $R$, was used to compute the radiative fraction of heat release, $F$, as given below:

$$
F=\frac{4 \pi L^{2} R}{\dot{m} \mathrm{LHV}}
$$

Here, $L$ is the distance from the flame centerline to the pyrheliometer, $\dot{m}$ is the mass flow rate of the liquid fuel, and LHV is the lower heating value of the fuel. The radiative fraction of heat released is the ratio of the total energy radiated by the flame to the net energy content of the burnt fuel.

3.3. Global and In-Flame Emission Measurement. The volumetric concentrations of $\mathrm{CO}_{2}, \mathrm{CO}$, and $\mathrm{NOx}$ in the exhaust were measured using a gas emissions analyzer. A conicalshaped flue was placed above the flame to collect the exhaust gases. At the top of the flue, a quartz probe with a $1 \mathrm{~mm}$ inner diameter was mounted to sample the exhaust gases. The exhaust gases were then passed through an ice bath to remove moisture and then through a filter to eliminate particulate matter. The concentration measurements of $\mathrm{CO}$ and NOx were then converted to emission indices on a mass basis ( $\mathrm{g}$ of species/kg of fuel) [15] to compensate for dilution:

$$
\mathrm{EI}_{i}=\left(\frac{X_{i}}{X_{\mathrm{CO}}+X_{\mathrm{CO}_{2}}}\right)\left(\frac{N \cdot \mathrm{MW}_{i}}{\mathrm{MW}_{f}}\right) .
$$

Here, $X_{i}$ represents the mole fraction, $N$ is the number of carbon atoms in the fuel, and MW is the molecular weight. It is assumed that all the carbon in the fuel is converted into $\mathrm{CO}$ and $\mathrm{CO}_{2}$ and that the soot concentration is small.

3.4. In-Flame Temperature Measurement. The radial temperature profiles were measured with an $R$ type thermocouple with a bead size of $0.3 \mathrm{~mm}$. The thermocouple was mounted on a traverse mechanism and was manually traversed through the flame. The thermocouple output was read and recorded with the help of a LabVIEW program at a sampling rate of $1 \mathrm{~Hz}$, and the temperatures were averaged over a period of 40 seconds. The temperature measurements were corrected for radiation, conduction, and convection losses [13].

3.5. Soot Volume Fraction Measurement. A $5 \mathrm{~mW}$ heliumneon laser with a power detector was used to measure the soot volume fraction in the flame. The laser beam attenuation due to the presence of the soot in the flame

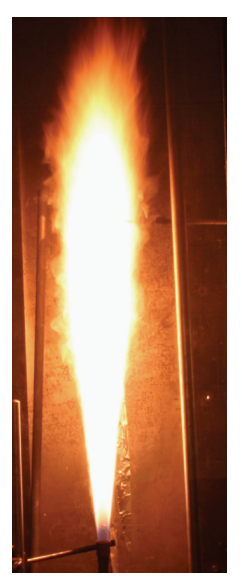

$\operatorname{Re}=2700$

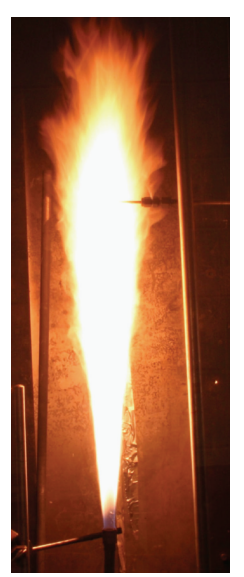

$\operatorname{Re}=3600$

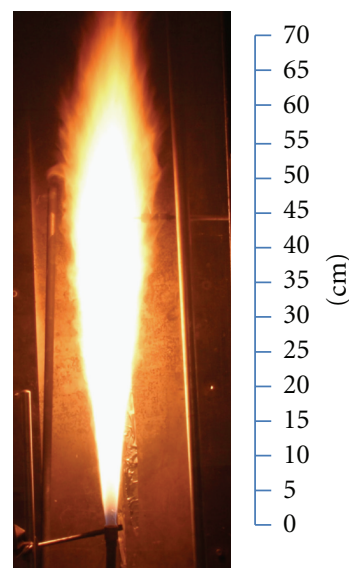

$\operatorname{Re}=4500$
Figure 2: Photographs of the CME B50 flames at three Reynolds numbers.

was obtained by measuring the laser beam intensity with no flame and through the flame. The flame intensity was also measured and subtracted from the total intensity measurements to get only the laser attenuation through the flame. The attenuation was then converted into soot volume fraction, $f_{v}$ :

$$
f_{v}=\frac{-\ln \left(I_{o} / I_{s}\right) \cdot \lambda}{k_{\lambda} \cdot \delta} .
$$

Here, $I_{o}$ is the attenuated laser intensity, $I_{s}$ is the incident laser intensity, $\lambda$ is the laser beam wavelength, and $\delta$ is the flame thickness along the laser beam length. The spectral extinction coefficient, $k_{\lambda}$, was assumed to be constant corresponding to that of petroleum diesel soot [16] in the calculations.

3.6. Exit Velocity Measurement. The exit vertical velocity of the fuel air mixture was measured with a laser Doppler velocimeter (LDV). The system was based on the $514.5 \mathrm{~nm}$ wavelength from an argon ion laser. Frequency shifting was used with a Bragg cell which shifted the frequency of one beam by $40 \mathrm{MHz}$; the signal was then downshifted by $38 \mathrm{MHz}$, yielding a net shift of $2 \mathrm{MHz}$. The scattered light was collected in the off-axis forward-scatter mode. Magnesium oxide $(\mathrm{MgO})$ particles of nominal diameter of 4 microns were used as seed particles. A fraction (20\%) of the air supply was diverted into the cylinder containing the $\mathrm{MgO}$ powder. The air intake port in the cylinder was positioned for tangential entry; the fine particles were carried through the exhaust port located at the center of the cylinder. The air carrying the seed particles was introduced $20 \mathrm{~cm}$ below the burner exit where it was mixed with the fuel-air mixture.

\section{Results and Discussion}

4.1. Flame Appearance. The flame images were captured with an 8-megapixel digital SLR camera at different shutter speeds. Typical flame images (long time exposure) of the B50 flame are presented in Figure 2 at the three Reynolds 


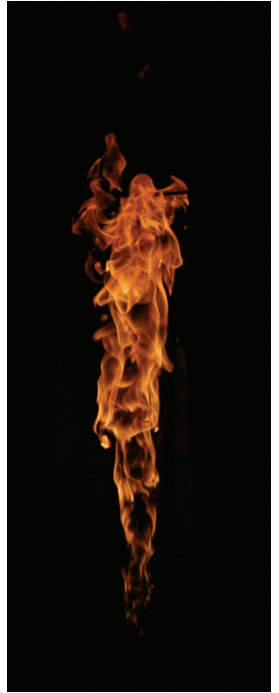

CME 2700

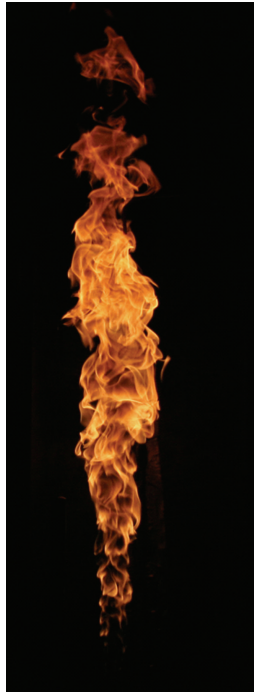

CME 3600

(b)

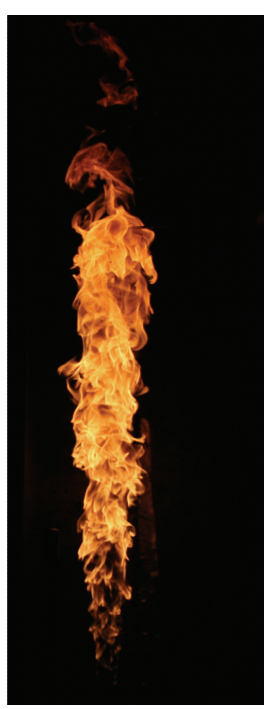

CME 4500

(c)
FIGURE 3: CME flame photographs with exposure time of $1 / 4000 \mathrm{~s}$.

numbers. The flames were brushy in appearance due to the turbulent conditions at the burner exit; this can be seen in the pictures in Figure 3 taken with an exposure time of $1 / 4000$ s. The presence of significant soot content in the flame provides the yellow hue. The exit equivalence ratio was 7; therefore, enough air was not supplied at the exit for complete combustion of the fuel and the air needed to be entrained from the surroundings. The flame heights for all the fuels were comparable. Near-burner exit images of pure CME and diesel flames are shown in Figure 4. These images were captured with an exposure time of $1 \mathrm{~s}$. The nearburner regions appear blue due to the dominant gas-phase reactions in this region. The blue region extended axially to larger heights as the biofuel content in the fuel was increased. The presence of oxygen in the fuel molecule of CME helps in the oxidation of the fuel, resulting in an increase in the homogeneous reaction zone near the burner.

4.2. Exit Velocity Profiles. The mean velocities of the fuelair mixture at the exit of the burner for the pure diesel and CME flames are given in Figure 5 for the three Reynolds numbers. In order to maintain an initial equivalence ratio of 7 , the amount of air supplied for the biofuel was smaller for each Reynolds number (due to the presence of oxygen in the fuel molecule); thus, the bulk velocity was lower for the biofuel flame than the diesel flame. This is observed in the mean velocity profiles. The peak axial velocity was attained at the centerline; the profiles are not flat because of the transitional nature of the flows at these Reynolds numbers. The mean centerline axial velocity was $22 \%$ higher than the bulk velocity. The corresponding turbulence intensities are presented in Figure 6. The turbulence intensities were higher near the edge than at the center (typical of a pipe flow). The maximum turbulence intensity (near the edge) increased with Reynolds number.
4.3. Flame Radiation. The radiative heat fraction for the various flames at the three Reynolds numbers is plotted in Figure 7. The flame radiation is emitted by the burning soot particles and the high-temperature gases present in the flame; it, thus, depends on the local temperature, gas emissivity, and soot emissivity. The radiative fraction of the pure CME flames was slightly lower than that of the diesel flames at all Reynolds numbers. In general, the soot content in the diesel flames was higher than that of the pure CME flames, but the maximum temperatures in the far-burner region were higher in the pure biofuel flames than in the diesel flames. Thus, the slightly lower radiative fraction in the pure CME flames could be attributed to the dominant effect of soot content in the flame. In the case of the flames of the blends, the radiative fraction of the B75 flame was higher than that of the diesel flame, whereas the radiative fractions of the B50 and B25 flames were comparable to the radiative fraction of the diesel flame. While the soot content in these flames was lower than that of the pure fuel flames, the flame temperatures differed from those measured in the pure fuel flames. The in-flame temperatures were highest for the B75 flame at 25 and 50\% flame heights, compared to the flames of the B25 and B50 blends [13]; the high temperatures resulted in the B75 flame having the highest radiation fraction.

In general, the radiative fraction increased as the Reynolds number was increased from 2700 to 3600 and then decreased with a further increase in Reynolds number to 4500 (except for the B50 flame). As noted earlier, the Reynolds number increase was achieved by increasing the bulk velocity, thereby increasing the air entrainment as the Reynolds number was increased. Thus, the highest radiative fraction at the Reynolds number of 3600 could be attributed to the tipping of the balance between the increased soot formation due to the larger carbon input rate and the higher soot oxidation rate with increased air entrainment.

4.4. Global Emissions. Figure 8 shows the global emission index of $\mathrm{CO}$ for all the flames. The $\mathrm{CO}$ emission index was lowest for the pure CME flame (one-third of the value of the diesel flame at a Reynolds number of 2700 and onehalf the value of the diesel flame at Reynolds numbers of 3600 and 4500). The B25 and B50 flames had a CO emission index comparable to that of the diesel flame whereas the $\mathrm{CO}$ emission index of the B75 flame was slightly lower than that of the diesel flame. As the biofuel content in the fuel is increased, the oxygen content in the fuel is increased, and the increased oxygen would be expected to help in the oxidation of $\mathrm{CO}$ to $\mathrm{CO}_{2}$. However, the global emission index of $\mathrm{CO}$ of the B25 flame was slightly higher than that of the diesel flame. This is a result of the coupling effect between CME and diesel. The carbon input rate in the diesel and B25 flames was comparable and higher than that of the B75 and pure CME flame (Table 1); the flame temperatures were lowest in the B25 flame at midflame and at 75\% flame heights. The soot volume fraction in the B25 flame was lower than that of the diesel flame (as discussed later). Thus, while less soot was formed in the B25 flame, the comparable carbon input rate resulted in higher $\mathrm{CO}$ formation. Also, the $\mathrm{CO}$ emission index decreased with an increase in Reynolds number for all 


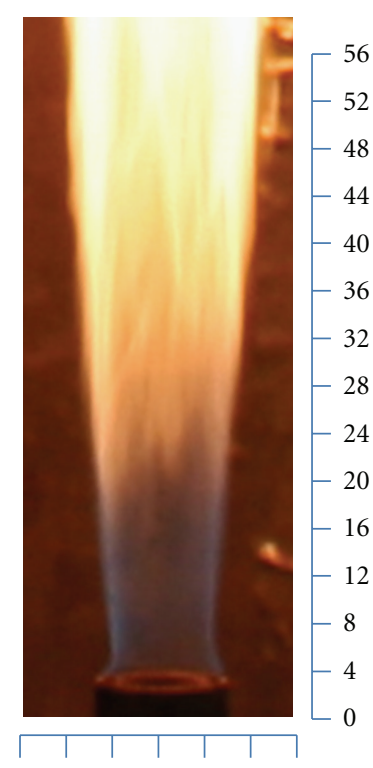

$\begin{array}{lllllll}24 & 20 & 16 & 12 & 8 & 4 & 0\end{array}$

CME 2700

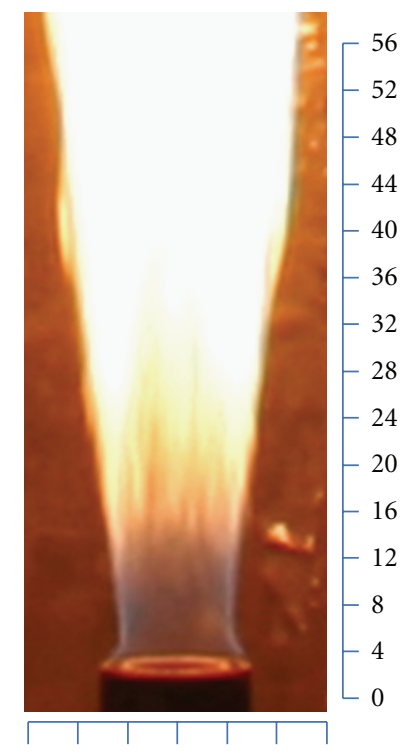

$\begin{array}{lllllll}24 & 20 & 16 & 12 & 8 & 4 & 0\end{array}$

Diesel 2700
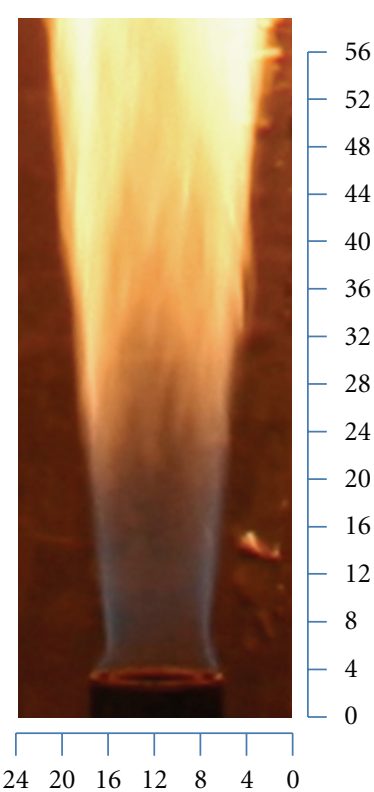

CME 3600

(a)

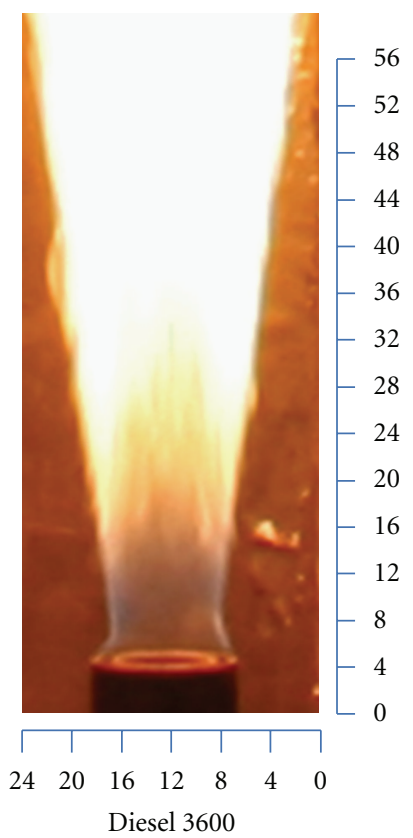

(b)
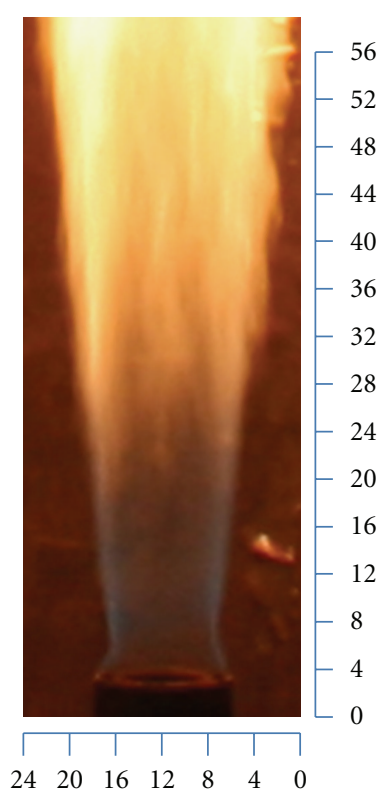

CME 4500

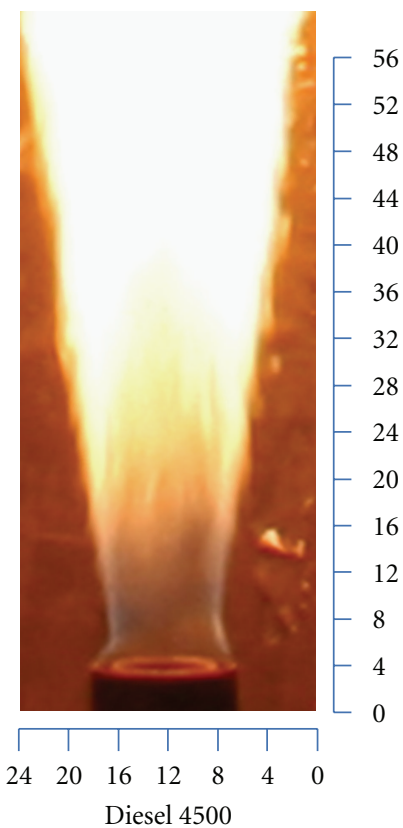

Figure 4: (a) Near-burner regions of CME flames (exposure time of $1 \mathrm{~s}$; dimensions in $\mathrm{cm}$ ). (b) Near-burner regions of diesel flames (exposure time of $1 \mathrm{~s}$; dimensions in $\mathrm{cm}$ ).

the fuels due to the higher air entrainment that occurred as the Reynolds number was increased.

The global NOx emission index measured in the various flames is presented in Figure 9. It was highest for the pure CME flame; in the case of the flames of the blends, the CME B25 flame had a higher NOx emission index than that of the diesel flame. NOx production in flames is governed by the thermal, Fenimore, and $\mathrm{N}_{2} \mathrm{O}$ mechanisms [15]. Thus, the local temperatures and the fuel-air mixture ratios play a significant role in the generation of NOx. In general, the maximum temperature in the flames of CME and CME blends were higher than that of the diesel flame, as described below. Therefore, NOx generation by the thermal mechanism could be significant at these conditions, in contrast to laminar flames at the same initial equivalence ratio [11]. The NOx emission index was found to increase with an increase in Reynolds number for most cases, except for the B50 and B75 flames, in which the NOx emission 


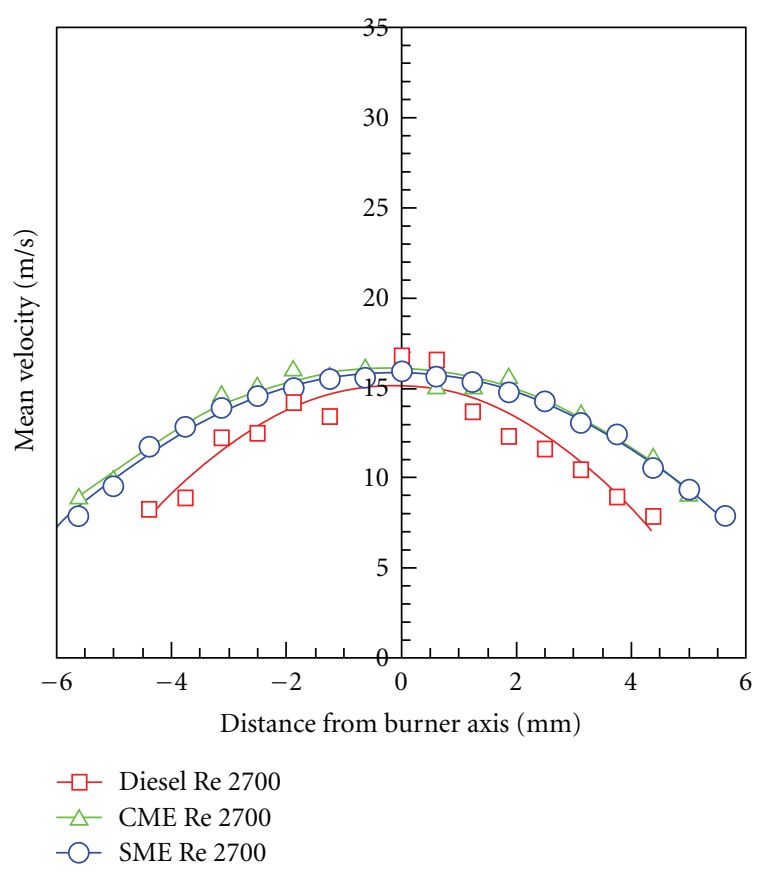

(a)

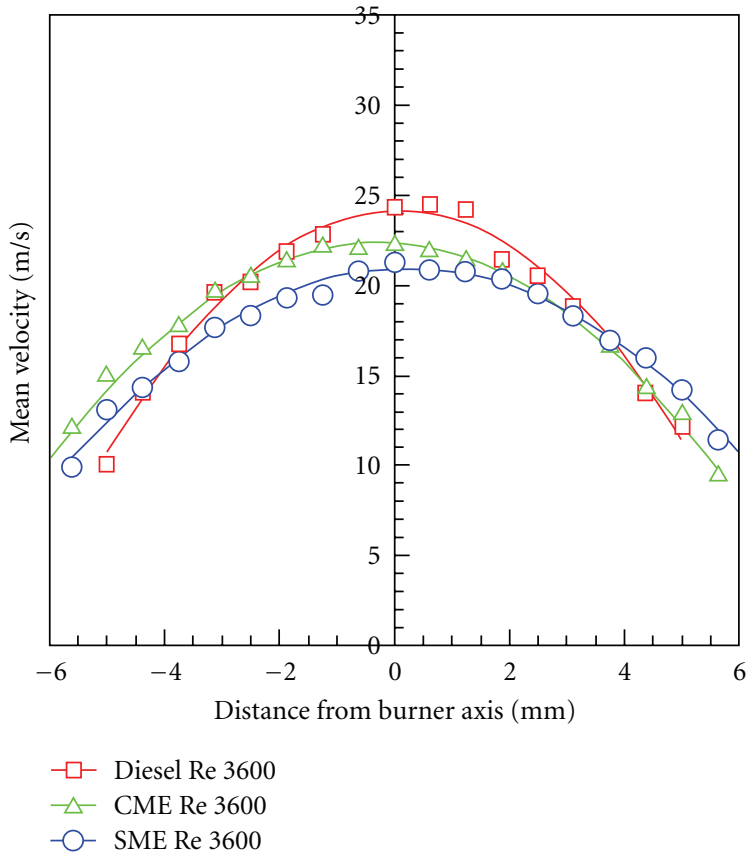

(b)

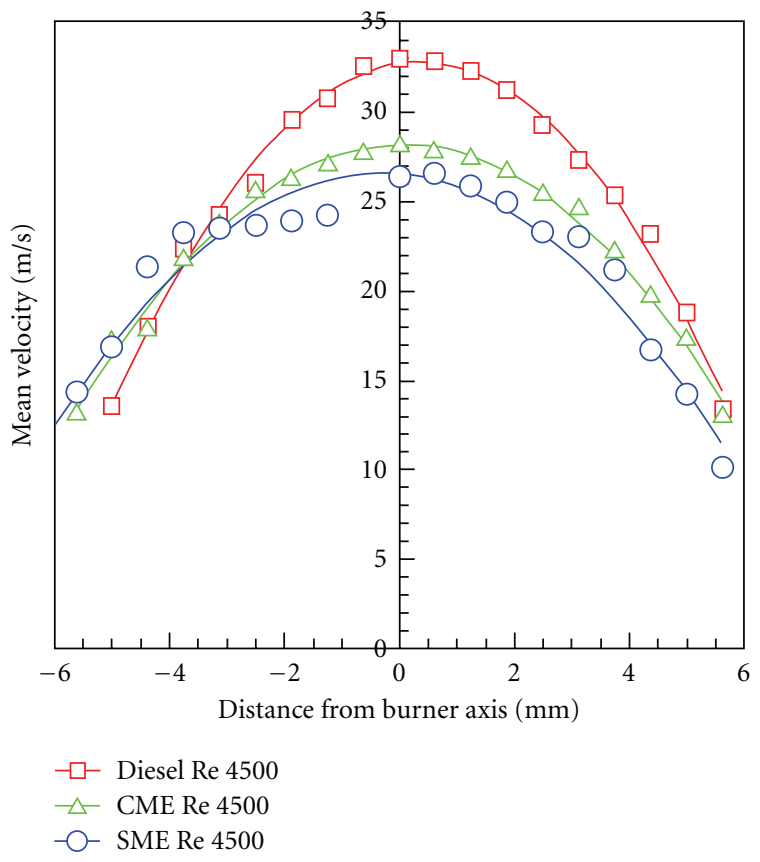

(c)

FIgure 5: Mean axial velocity profiles at the burner exit.

index dropped at the Reynolds number of 3600 and increased at a Reynolds number of 4500 . The larger air entrainment at higher Reynolds numbers leading to leaning of the local mixtures, and the shorter residence times (due to higher velocities) affect the thermally formed NOx in opposite directions, and thus could be a reason for the minimum observed at the Reynolds number of 3600 for the B50 flame.
4.5. Temperature Profiles. Figure 10 shows the radial temperature profiles in the flames at three-quarter flame height. The effect of Reynolds number $(\mathrm{Re}=2700,3600$, and 4500) can be seen by comparing the three figures. In each figure, the effect of blend ratio at a given Reynolds number is presented. At this axial location, the temperature reached a maximum near the centerline and decreased as the radial distance was increased for all flames except for the B75 


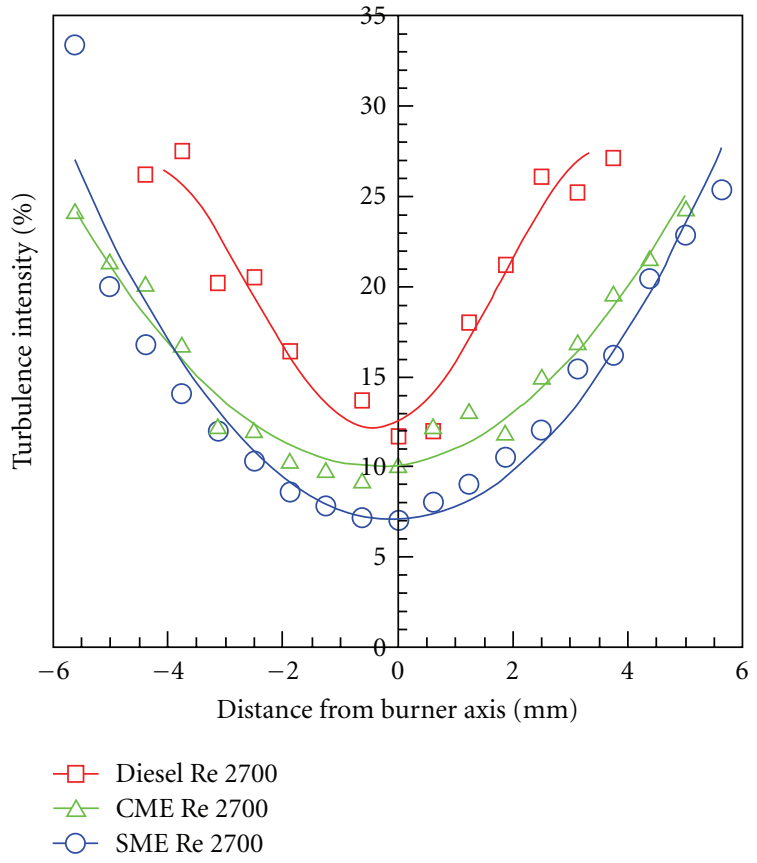

(a)

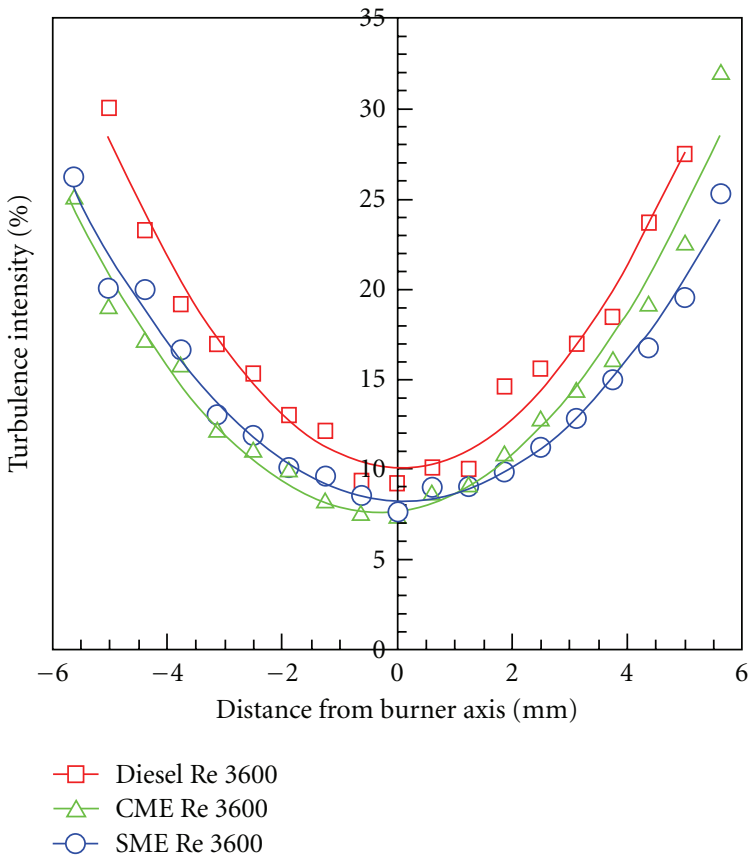

(b)

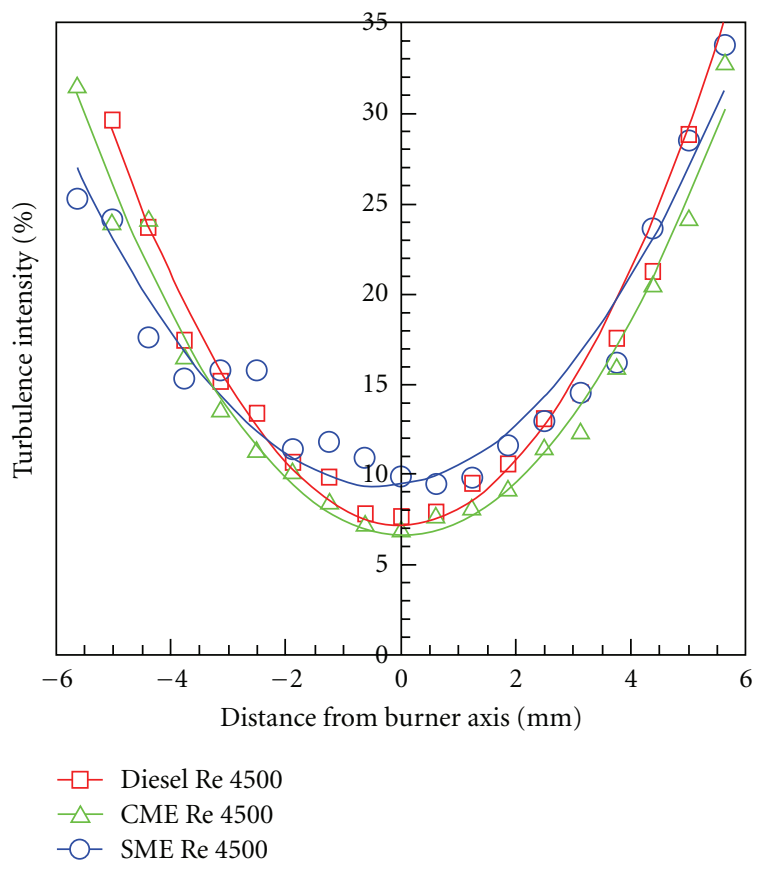

(c)

FIGURE 6: Axial velocity turbulence intensity profiles at the burner exit.

flame, which shows an off-axis peak that is particularly dominant at $\operatorname{Re}=4500$. This trend is characteristic of sootdominated heterogeneous combustion in the far-burner regions of high initial equivalence ratio premixed flames. At the highest Re (4500), the combined effect of soot reduction and cumulative air entrainment could make homogeneous gas-phase reactions significant, resulting in off-axis peaks in radial temperature profiles. That seems to be the case for the flame of the CME B75 blend.

Since the local equivalence ratio is determined by the soot concentration and cumulative air entrainment up to this region, it can approach stoichiometric or even lean condition. Hence, the maximum temperature that could occur is limited by the adiabatic flame temperature 


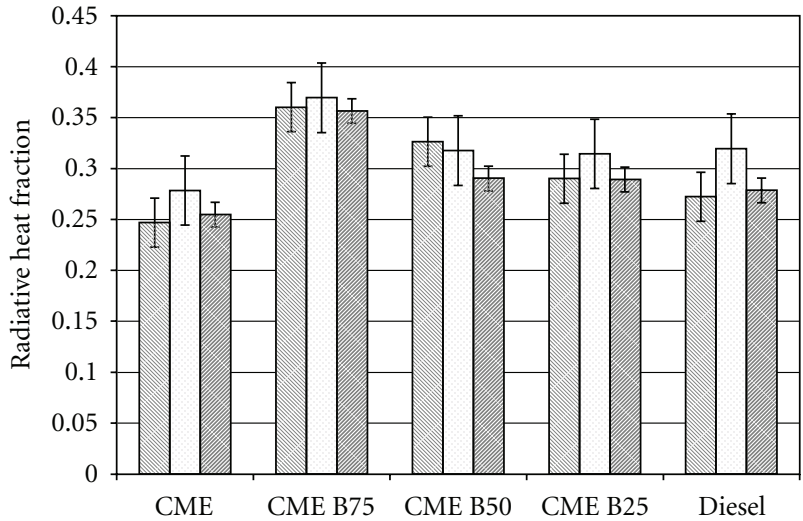

$\square \operatorname{Re} 2700$

ㅁ $\operatorname{Re} 3600$

만 4500

Figure 7: Comparison of radiative heat fraction of the different flames.

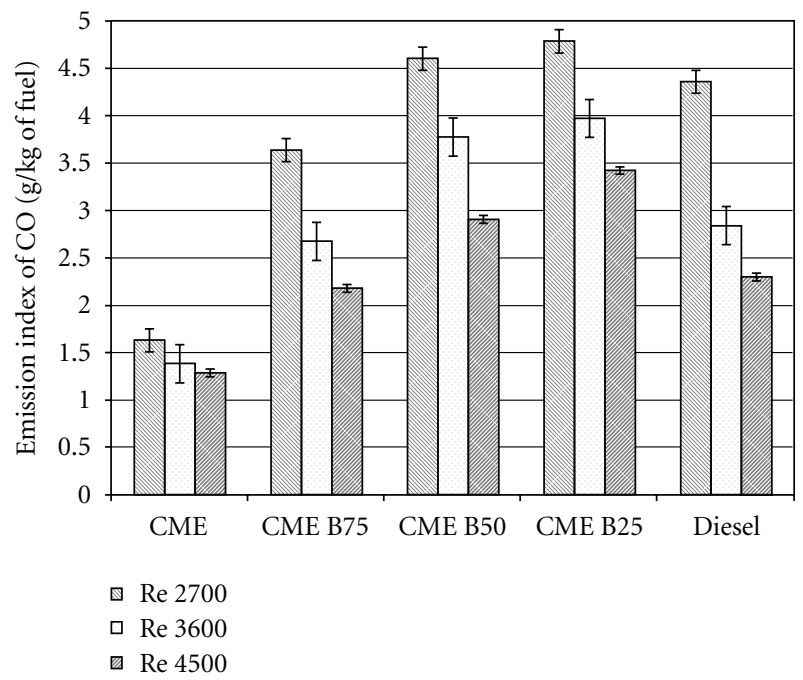

Figure 8: Comparison of CO emission index of various flames.

(2303 K for pure diesel, $2300 \mathrm{~K}$ for CME B25, $2297 \mathrm{~K}$ for CME B50, $2294 \mathrm{~K}$ for CME B75, and $2291 \mathrm{~K}$ for CME). The temperature in the pure CME flame was the highest at this location. At a Reynolds number of 2700, the temperatures in the diesel and B75 flame were comparable and higher than those of the B25 and B50 flames; the temperatures in the B25 and diesel flames were the lowest at the Reynolds numbers of 3600 and 4500 . The peak temperature increased with Reynolds number due to better mixing between the surrounding air and the partially premixed fuel/air mixture.

4.6. Soot Volume Fraction. The axial variation of soot volume fraction in the flames is presented in Figure 11. In general, the soot volume fraction increased with downstream distance. In the flames of the CME blends, the soot volume fraction decreased near the flame tip, particularly at the

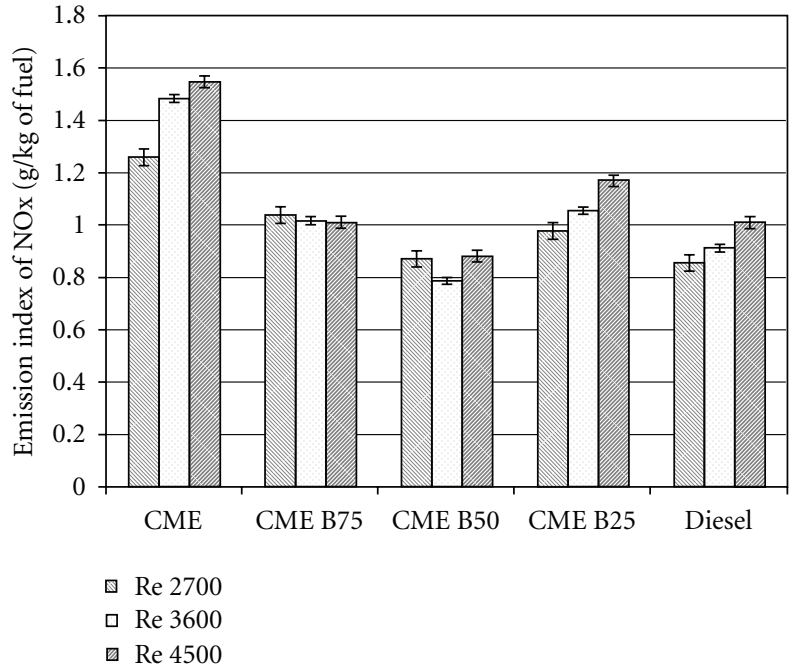

Figure 9: Comparison of NOx emission index of various flames.

Reynolds number of 4500. The diesel flame had the highest soot volume fraction, followed by the pure biofuel flame. The presence of oxygen in the fuel molecule of CME would be expected to reduce the formation of soot in the biofuel flames. It is interesting that the soot volume fraction in the flames of the CME blends was lower than that of the pure CME flames. The fuel with high carbon/hydrogen ratio (diesel) and oxygen in the fuel molecule that can enhance soot pyrolysis rate (CME) can yield high soot concentrations overall. Thus, the pure diesel and CME flames have higher soot concentrations than their blends.

In the near-burner region $(x / L<0.35)$, the residence time of the fuel at $\mathrm{Re}=2700$ is much larger than that at $\operatorname{Re}=4500$. Fuel pyrolysis, soot nucleation, and particle growth are dominant in this region compared to oxidation reactions. Hence, at $\operatorname{Re}=2700$, the differences in the fuel molecular structure manifest themselves as significant differences in soot volume fraction. Due to higher velocities and entrainment of additional air that promote oxidation reactions also, these difference are mitigated at $\mathrm{Re}=4500$. The synergistic coupling effect between CME and diesel fuels appears to be dominant in these flames. The insignificant change in soot volume fraction with the increase in Reynolds number was a result of the cumulative overall effect of higher carbon input rate and higher dilution due to increased air entrainment.

4.7. In-Flame NOx Concentration. Figure 12 shows the inflame concentration measurement of NOx at three-quarter flame height. At this flame height, the peak NOx concentration occurred at the centerline and decreased towards the flame edge, although slight off-axis hump is seen for the B75 flame at $\mathrm{Re}=2700$. The peak NOx concentrations were recorded for the pure CME flames, which also had the highest in-flame temperatures [13]. Further, the Zeldovich thermal NOx mechanism shows that NOx formation rate also depends upon the local oxygen concentration The NOx concentrations were lowest for the pure diesel flames. 


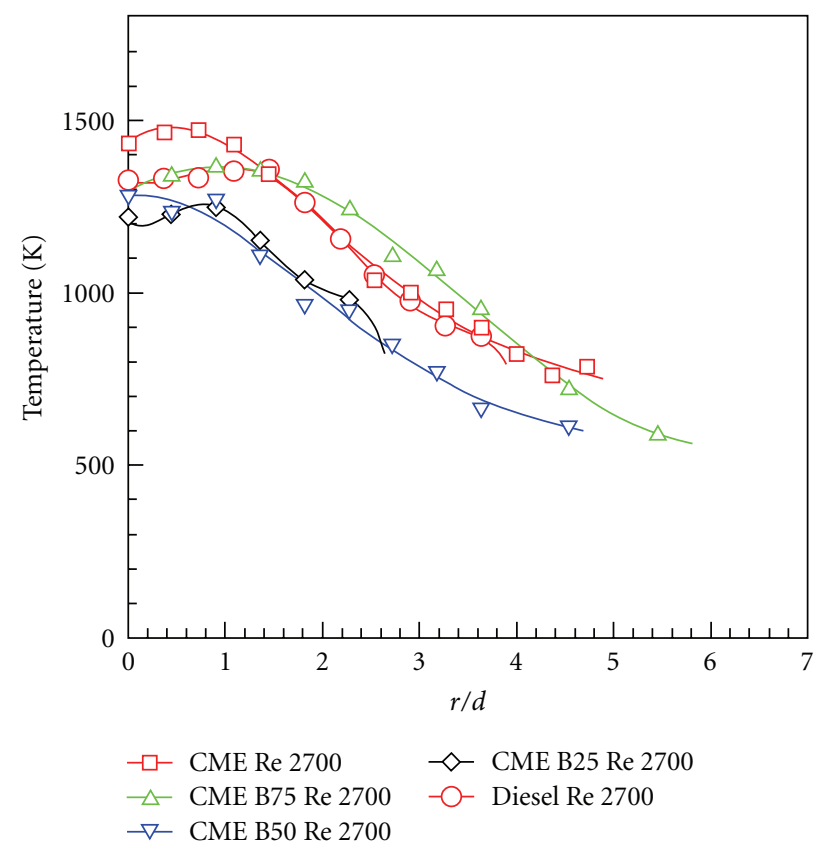

(a)

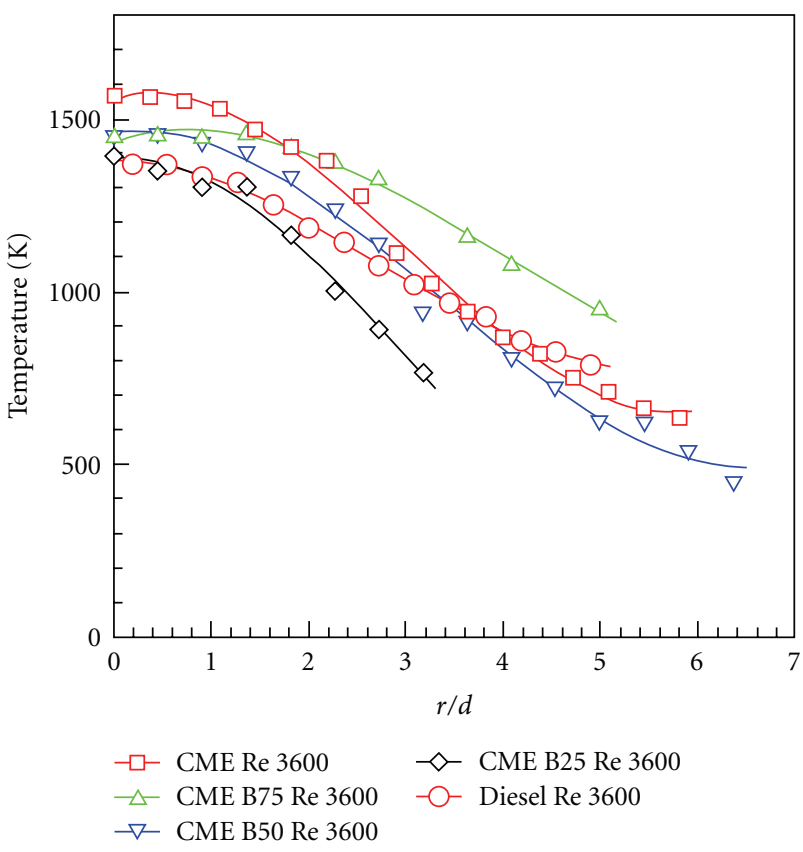

(b)

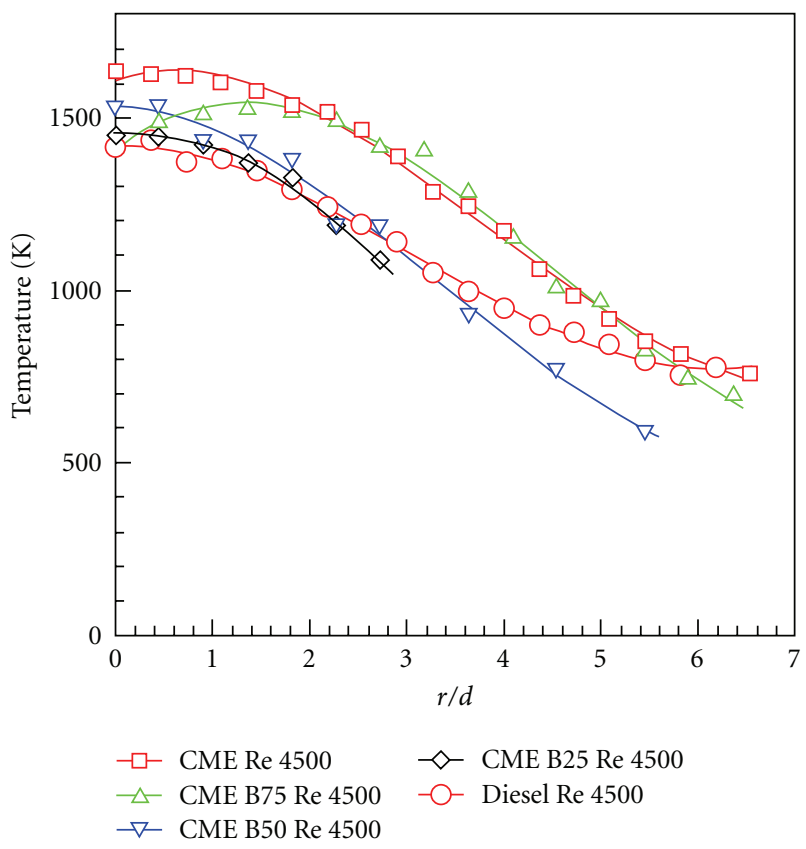

(c)

FIGURE 10: Radial temperature profiles of the flames at three-quarter flame height.

Biofuels carry over $10 \%$ of oxygen by mass with them, which suggests the dominance of the thermal route for NOx formation. As the Reynolds number was increased, the peak NOx concentration increased. These trends follow those of the temperature measurements, as shown in Figure 10, confirming that the thermal mechanism of NOx formation was dominant in the CME flames under these conditions. The variance of this result with laminar flame observations [11] highlights the effects of turbulence on the structure and emissions of biofuel flames.

\section{Conclusions}

Measurements were made in turbulent flames of CME and three CME/diesel blends (B25, B50, and B75) for three burner exit Reynolds numbers of 2700, 3600, and 4500. The burner exit equivalence ratio was kept constant at 7. Based on the measurements, the following conclusions were drawn.

(1) The flames of all the fuels were of comparable height, ranging from $50-65 \mathrm{~cm}$. In the near-burner region, 


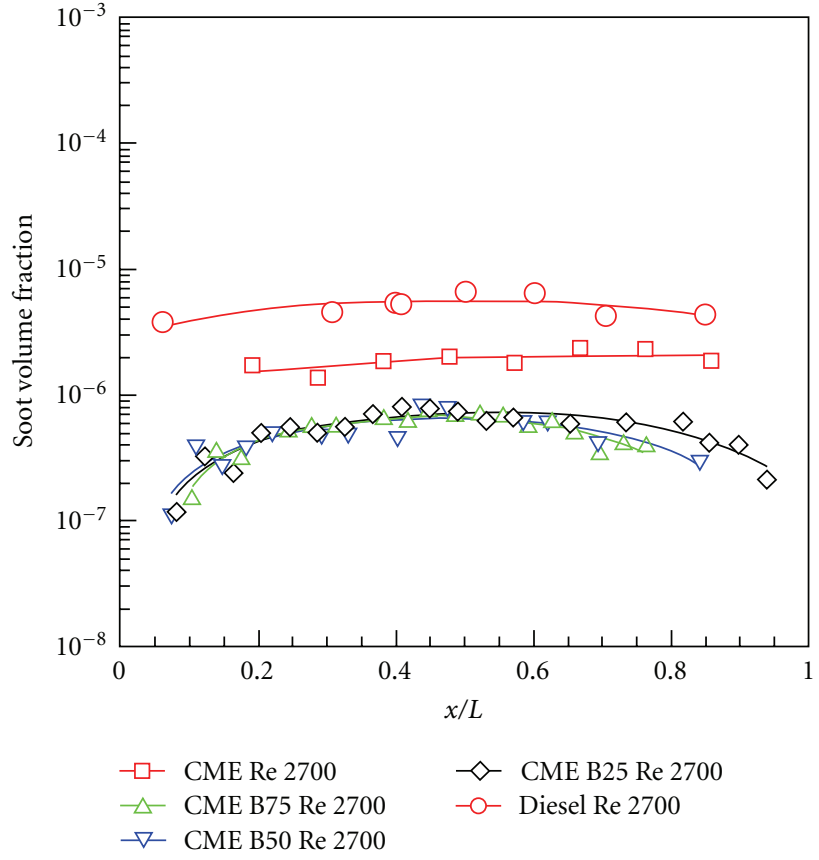

(a)

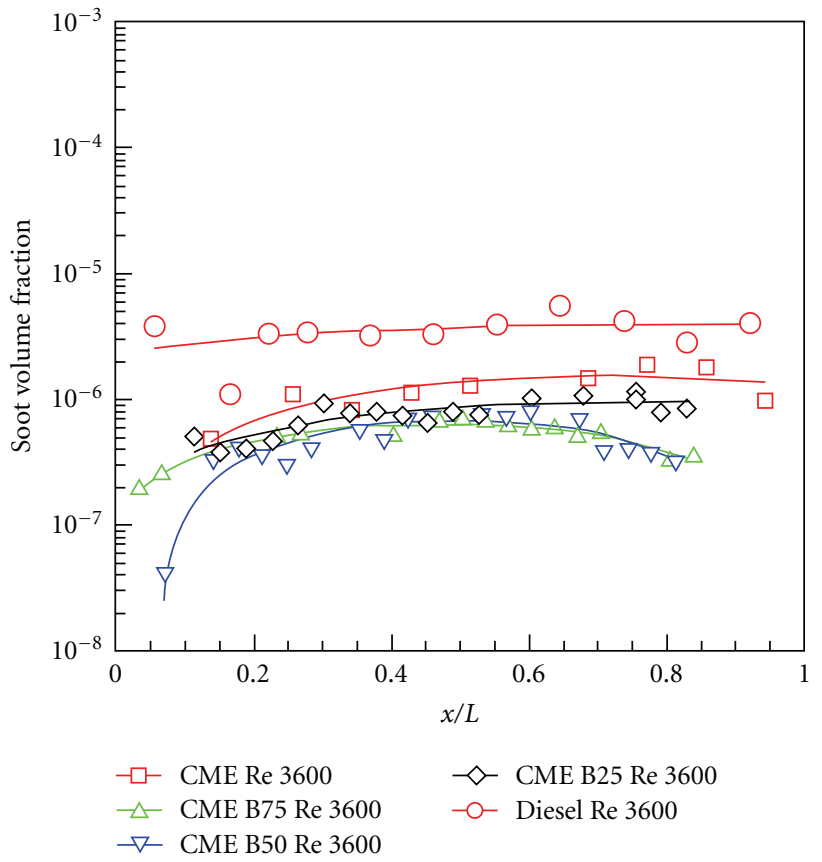

(b)

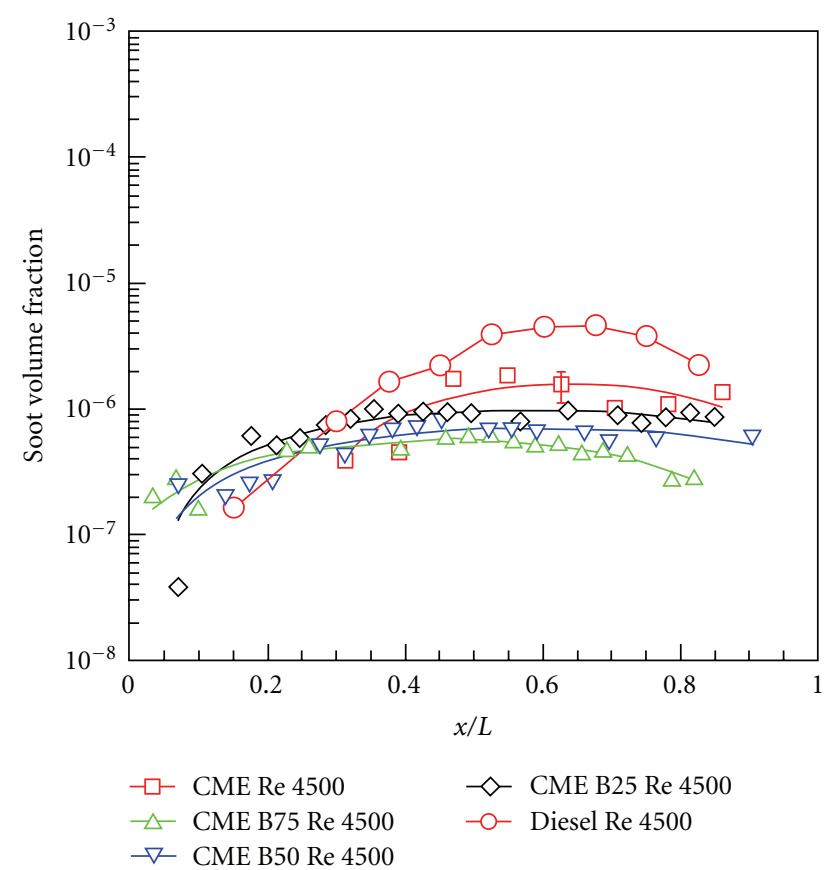

(c)

FIgURE 11: Axial profiles of soot volume fraction.

the length of the homogeneous gas-phase reactions (indicated by blue hue) was longer for the CME flames. The presence of oxygen in the fuel molecule of CME promoted the oxidation of the fuel in the nearburner region.

(2) The soot volume concentration in the flames of the CME blends was lower than that of the flames of the pure fuels, highlighting the combined effect of the reduction in soot precursor oxidation (due to the presence of oxygen in the biofuels) and the higher degree of pyrolysis of diesel. As the Reynolds number was increased, the soot volume concentration did not change significantly due to the cumulative overall effect of higher carbon input and higher air entrainment. 


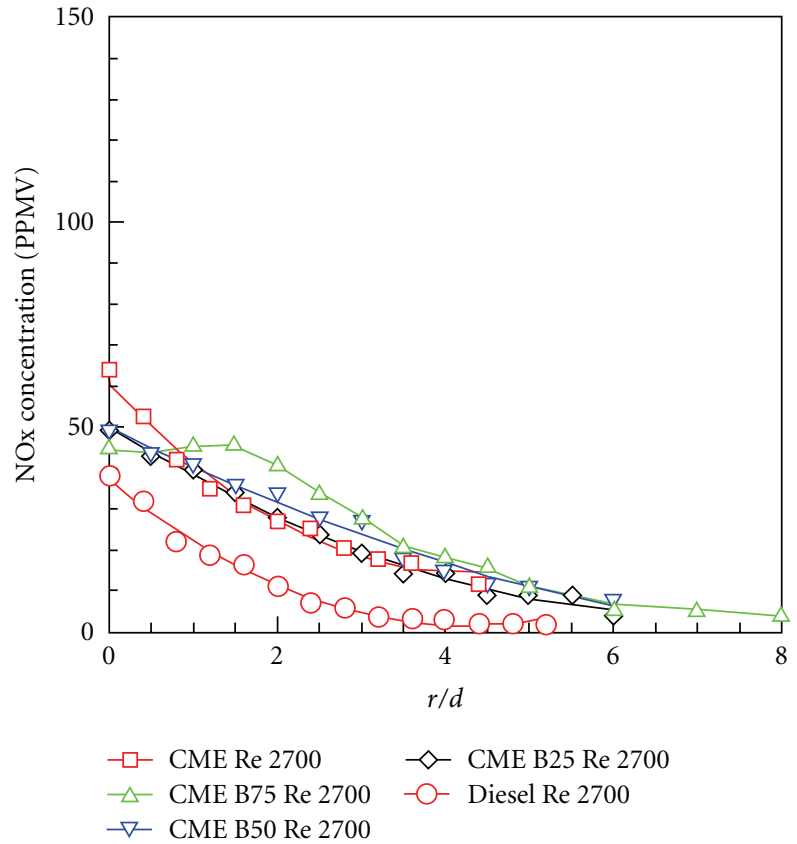

(a)

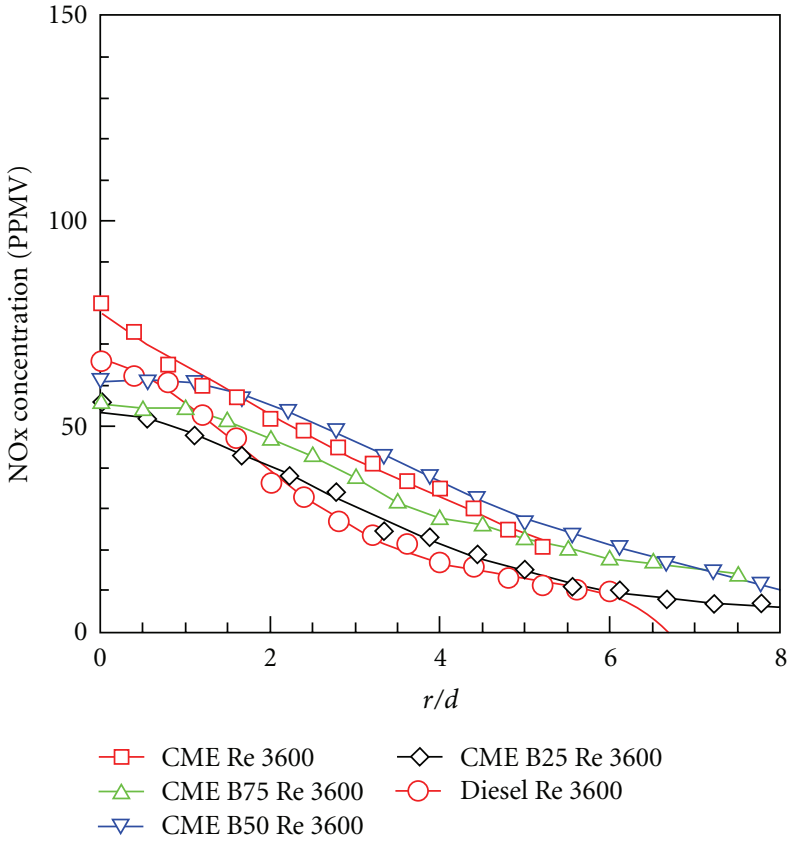

(b)

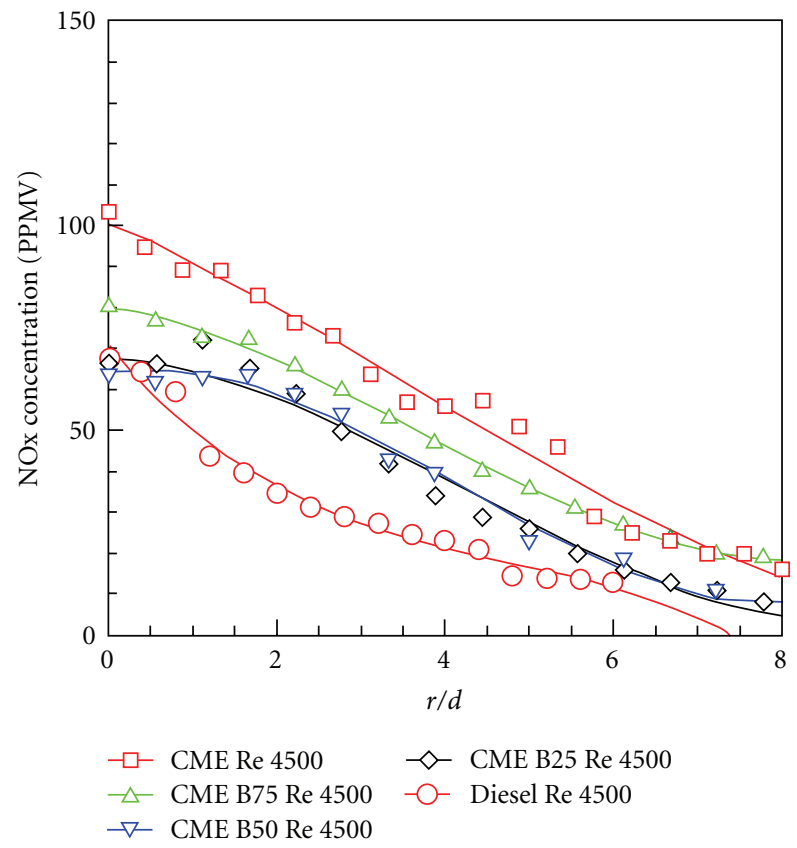

(c)

FIgURE 12: Radial profiles of NOx concentrations in the flames at three-quarter flame height.

(3) The radiative heat fraction of the B75 flame was higher than that of the other flames. Whereas the soot content in the flames of the blends was lower than that of the pure fuel flames, the temperatures at mid flame and three-quarter flame heights were higher for the flames of the blends. The lower amount of soot appeared to burn at a higher rate, thereby increasing the energy release rate with the same amount of air entrained at a given Reynolds number.
(4) The CO emission index decreased with an increase in Reynolds number due to the increase in air entrainment.

(5) The global NOx emission index was highest for the pure CME flame. At three-quarter flame height, the NOx concentrations in the flames were lowest for the pure diesel flame, and increased with Reynolds number. These trends corresponded to those of 
the flame temperatures, indicating that the thermal formation of NOx was dominant in these flames.

(6) Finally, the measurements indicate that the combustion characteristics of the turbulent flames of $\mathrm{CME} /$ diesel blends cannot be predicted accurately based on the blend ratio and properties of pure CME and diesel flames. Detailed in-flame measurements of radical concentrations are required to understand the formation of $\mathrm{CO}$ and $\mathrm{NOx}$ in the flames of blended fuels.

\section{Nomenclature}

F: $\quad$ Radiative fraction of heat release

$f_{v}: \quad$ Soot volume fraction

$k_{\lambda}$ : Spectral coefficient of light attenuation

$L$ : $\quad$ Distance between flame and radiometer, $\mathrm{m}$

LHV: Lower heating value of the fuel, $\mathrm{kJ} / \mathrm{kg}$

$\dot{m}$ : Fuel mass flow rate, $\mathrm{kg} / \mathrm{s}$

MW: Molecular weights

$N$ : Number of carbon atoms in fuel

$\mathrm{R}: \quad$ Measured flame radiation

X: Mole fraction

$\delta: \quad$ Flame thickness, $\mathrm{cm}$

$\lambda$ : $\quad$ Laser wavelength.

\section{Acknowledgment}

The financial support provided by the US Department of Energy is gratefully acknowledged.

\section{References}

[1] T. D. Durbin, J. R. Collins, J. M. Norbeck, and M. R. Smith, "Effects of biodiesel, biodiesel blends, and a synthetic diesel on emissions from light heavy-duty diesel vehicles," Environmental Science and Technology, vol. 34, no. 3, pp. 349$355,2000$.

[2] K. W. Scholl and S. C. Sorenson, "Combustion of soybean oil methyl ester in a direct injection diesel engine," in International Congress and Exposition, pp. 211-223, March 1993.

[3] R. L. McCormick, M. S. Graboski, T. L. Alleman, A. M. Herring, and K. S. Tyson, "Impact of biodiesel source material and chemical structure on emissions of criteria pollutants from a heavy-duty engine," Environmental Science and Technology, vol. 35, no. 9, pp. 1742-1747, 2001.

[4] W. G. Wang, D. W. Lyons, N. N. Clark, M. Gautam, and P. M. Norton, "Emissions from nine heavy trucks fueled by diesel and biodiesel blend without engine modification," Environmental Science and Technology, vol. 34, no. 6, pp. 933939, 2000.

[5] M. P. Dorado, E. Ballesteros, J. M. Arnal, J. Gómez, and F. J. López, "Exhaust emissions from a Diesel engine fueled with transesterified waste olive oil," Fuel, vol. 82, no. 11, pp. 13111315, 2003.

[6] G. Labeckas and S. Slavinskas, "The effect of rapeseed oil methyl ester on direct injection Diesel engine performance and exhaust emissions," Energy Conversion and Management, vol. 47, no. 13-14, pp. 1954-1967, 2006.
[7] A. K. Agarwal, "Biofuels (alcohols and biodiesel) applications as fuels for internal combustion engines," Progress in Energy and Combustion Science, vol. 33, no. 3, pp. 233-271, 2007.

[8] C. J. Mueller, A. L. Boehman, and G. C. Martin, "An experimental investigation of the origin of increased $\mathrm{NO}$ emissions when fueling a heavy-duty compression-ignition engine with soy biodiesel," in Powertrains, Fuels and Lubricants Meeting, June 2009.

[9] M. Kousoulidou, G. Fontaras, L. Ntziachristos, and Z. Samaras, "Biodiesel blend effects on common-rail diesel combustion and emissions," Fuel, vol. 89, no. 11, pp. 34423449, 2010.

[10] N. D. Love, R. N. Parthasarathy, and S. R. Gollahalli, "Rapid characterization of radiation and pollutant emissions of biodiesel and hydrocarbon liquid fuels," Journal of Energy Resources Technology, vol. 131, no. 1, Article ID 012202, 2009.

[11] N. D. Love, R. N. Parthasarathy, and S. R. Gollahalli, "Effect of iodine number on $\mathrm{NO}$ formation in laminar flames of oxygenated biofuels," International Journal of Green Energy, vol. 6, no. 4, pp. 323-332, 2009.

[12] J. A. Erazo Jr., R. Parthasarathy, and S. Gollahalli, "Atomization and combustion of canola methyl ester biofuel spray," Fuel, vol. 89, no. 12, pp. 3735-3741, 2010.

[13] N. Dhamale, Combustion properties of Partially Pre-mixed Blends of Canola Methyl Ester and Soy Methyl Ester With No. 2 Diesel Fuel under Turbulent Flame Conditions, M.S. thesis, School of Aerospace and Mechanical Engineering, University of Oklahoma, Norman, Okla, USA, 2010.

[14] C. R. Wilke, "Diffusional properties of multicomponent gases," Chemical Engineering Progress, vol. 46, pp. 95-101, 1950.

[15] S. Turns, An Introduction to Combustion, McGraw Hill, New York, NY, USA, 2nd edition, 2000.

[16] D. J. Bryce, N. Ladommatos, and H. Zhao, "Quantitative investigation of soot distribution by laser-induced incandescence," Applied Optics, vol. 39, no. 27, pp. 5012-5022, 2000. 

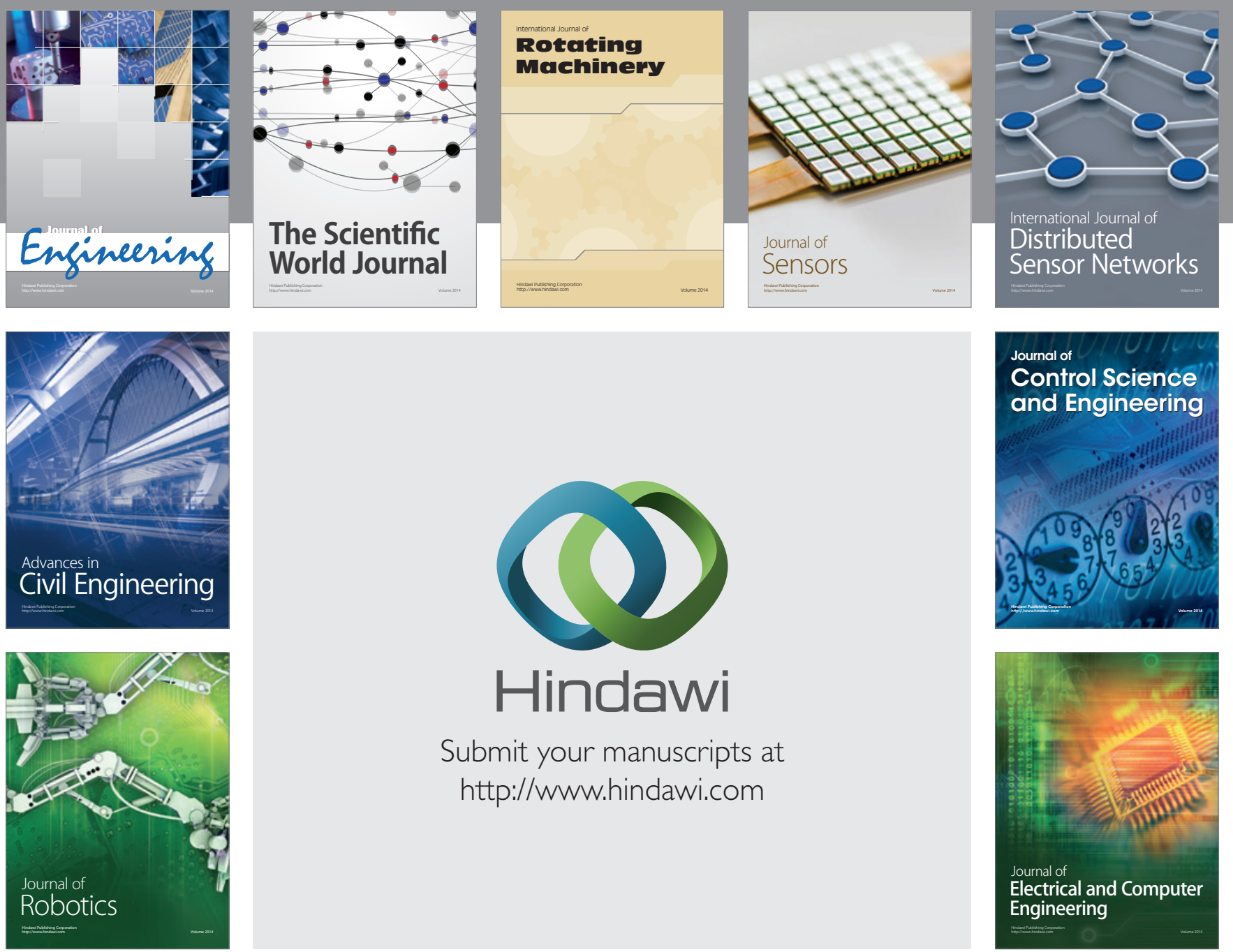

Submit your manuscripts at

http://www.hindawi.com
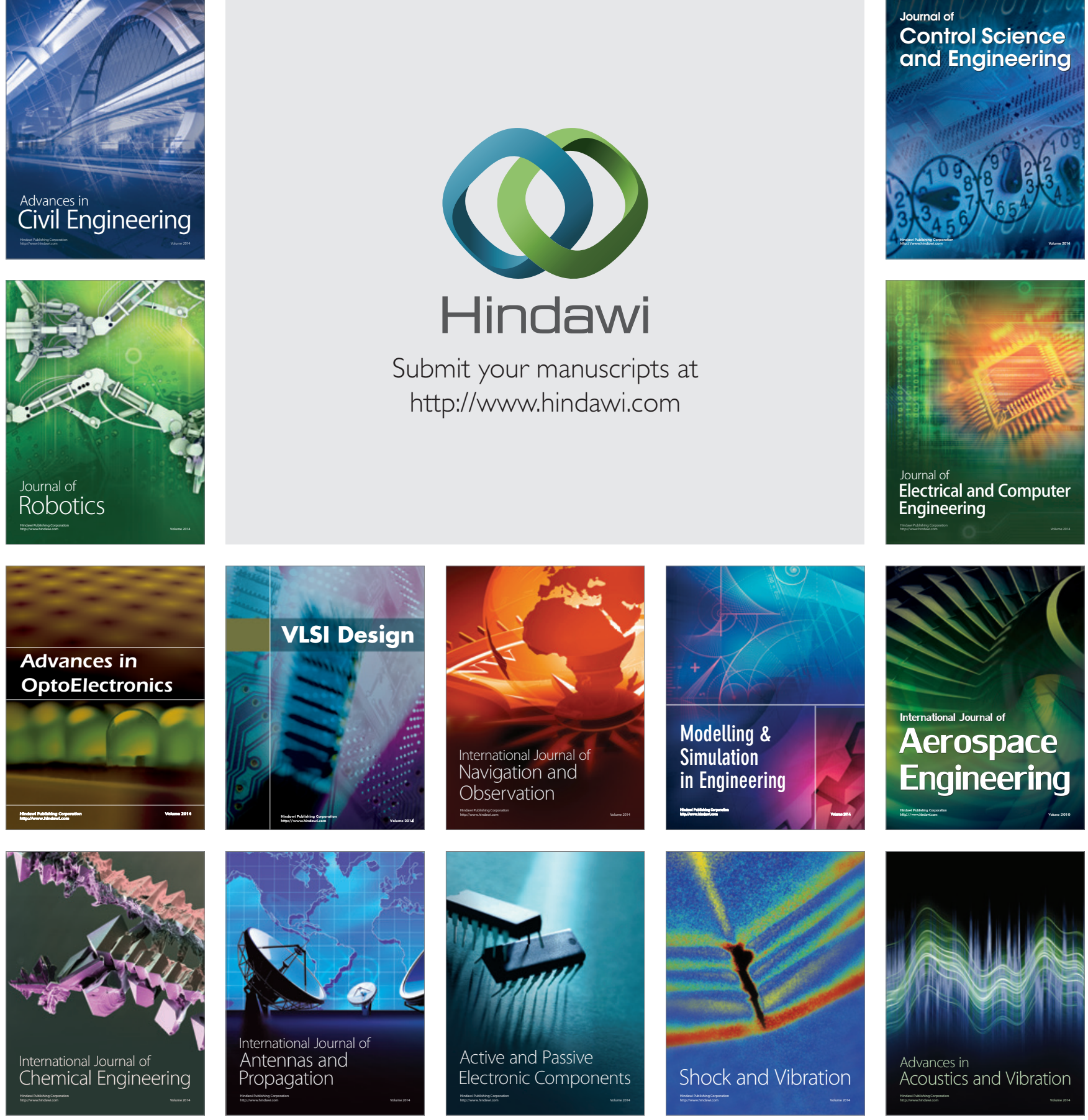